Supplement of Earth Surf. Dynam., 6, 1-27, 2018 https://doi.org/10.5194/esurf-6-1-2018-supplement (C) Author(s) 2018. This work is distributed under the Creative Commons Attribution 3.0 License.

(c) (1)

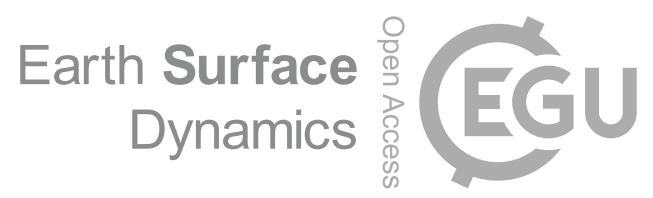

Supplement of

\title{
Developing and exploring a theory for the lateral erosion of bedrock chan- nels for use in landscape evolution models
}

\author{
Abigail L. Langston and Gregory E. Tucker \\ Correspondence to: Abigail L. Langston (alangston@ksu.edu)
}

The copyright of individual parts of the supplement might differ from the CC BY 3.0 License. 


\section{Flow chart of model steps:}

This section details the steps taken by the model during one time step.

1. Parameters such as time step, $\mathrm{Kv}, K_{l} / K_{v}$ ratio, $\alpha$, (and position and drainage area of inlet node, if desired) are passed to the lateral erosion component.

2. Flow is routed over the landscape using the Landlab flow routing component, returning discharge, drainage area, flow direction, and maximum slope for each grid node.

3. Working from upstream to downstream, the following is done at each node:

- Vertical erosion and deposition are calculated at each node using equation 8b and equation 3 from the main paper.

- The lateral neighbor node for each primary node is identified.

- If the lateral node is not a boundary node and is higher in elevation than the primary node, lateral erosion is calculated with equation $13 \mathrm{~b}$.

- The volume eroded laterally at this node is calculated by $E_{l} \times d x \times H$ and the value is stored in an array called vollat.

- Sediment that was eroded vertically and laterally is sent to the downstream node as volumetric sediment flux $\left(Q_{s}\right)$. If deposition occurs downstream, deposited material is treated as bedrock, not a separate sediment layer.

4. An internal time step check is executed to ensure model stability.

5. Going from upstream to downstream, the model determines if enough lateral erosion has occurred to change the height of the node.

- The volume of sediment that must be eroded from the lateral node so that its elevation is equal to the downstream node is calculated (voldiff). How voldiff is calculated depends on the chosen model formulation. See numerical implementation section for details.

- If the cumulative volume eroded from the lateral node (vollat $\left[\right.$ lat $\left._{\text {node }}\right]$ ) is greater than or equal to voldiff, the lateral node will be eroded to the elevation of the downstream node.

6. The node elevations are updated with calculated vertical and lateral erosion.

7. If the internal time step was shorter than the storm duration (model time step), the model begins again.

8. If the model has run to $0.01 \%$ of storm duration, the flow routing is run again for plotting, and output files are written.

\section{Lateral node selection and radius of curvature calculation}

The figures below show how lateral nodes are chosen based on flow directions and how radius of curvature is calculated for the three different possible scenarios: straight stream segments, stream segments at a $45^{\circ}$ angle, and stream segments at a $90^{\circ}$ angle. 


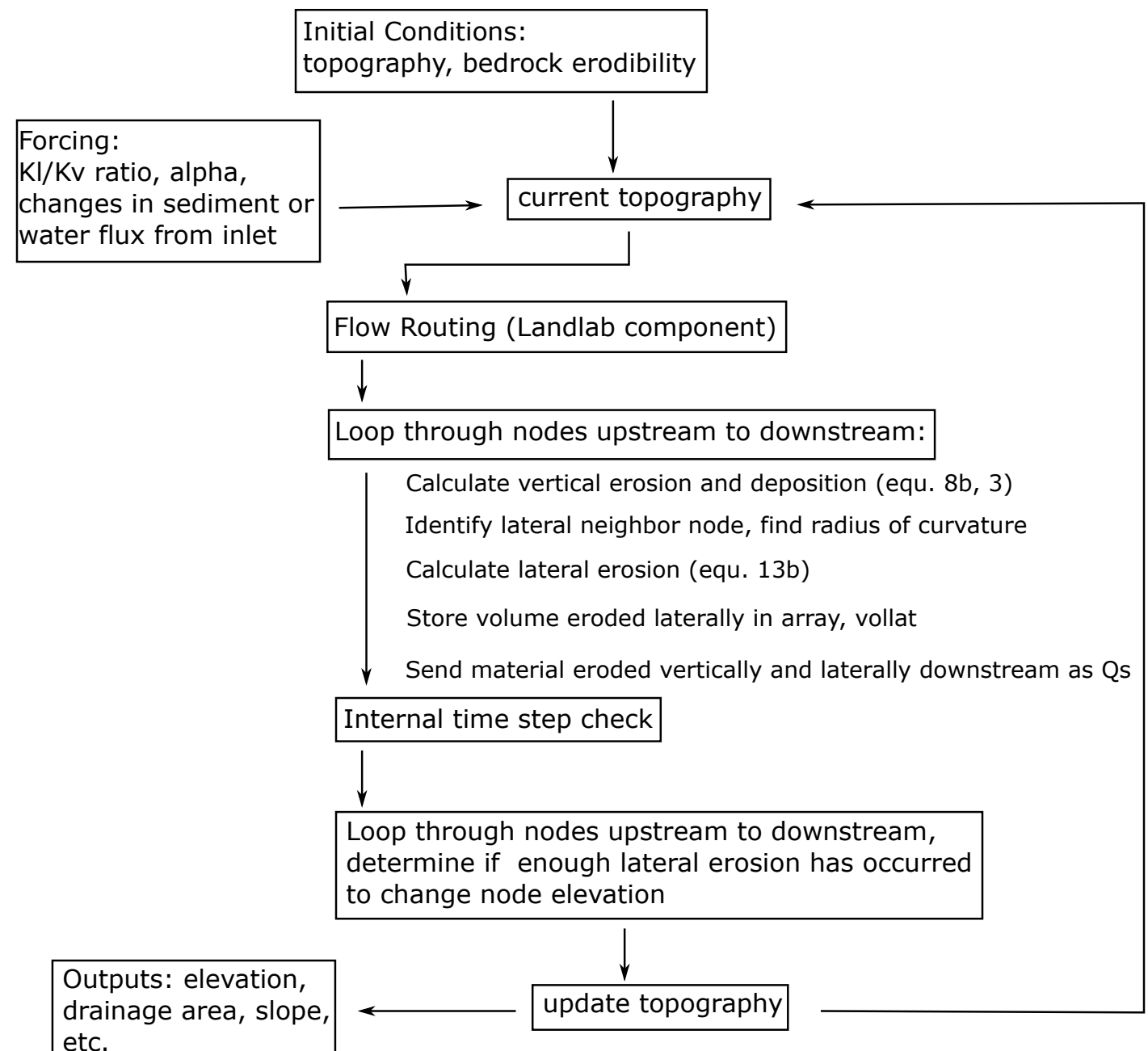

Figure 1: Flow chart showing steps taken by the model during one time step.
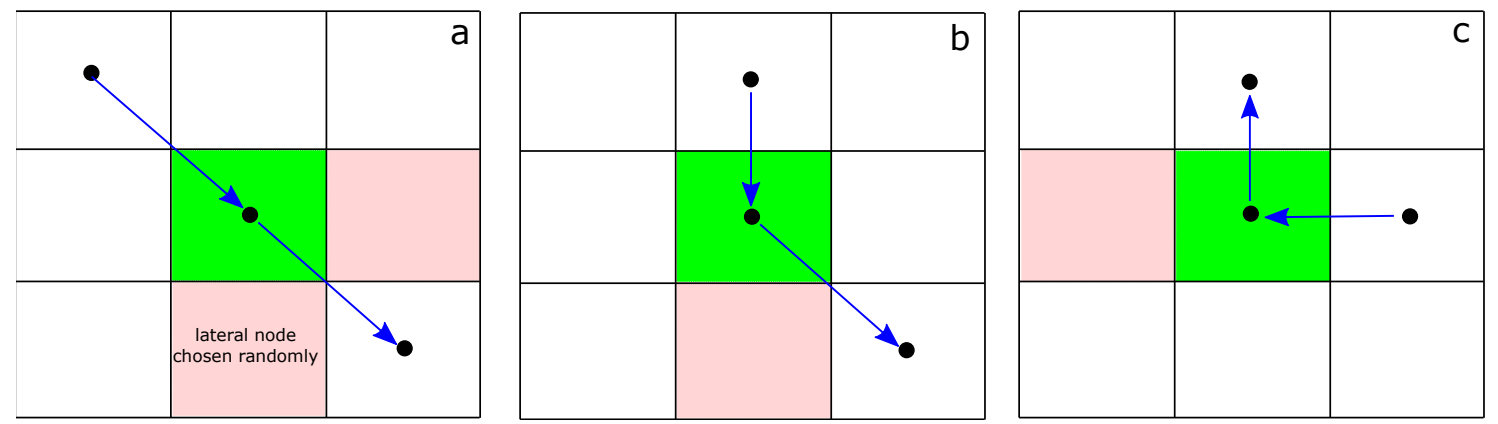

Figure 2: Schematic showing how lateral nodes are chosen in three example cases. The primary node is shown in green and erodes vertically. The lateral node is shown in pink and erodes laterally. a) Straight stream segment across diagonal b) $45^{\circ}$ bend in stream segment c) $90^{\circ}$ bend in stream segment. 


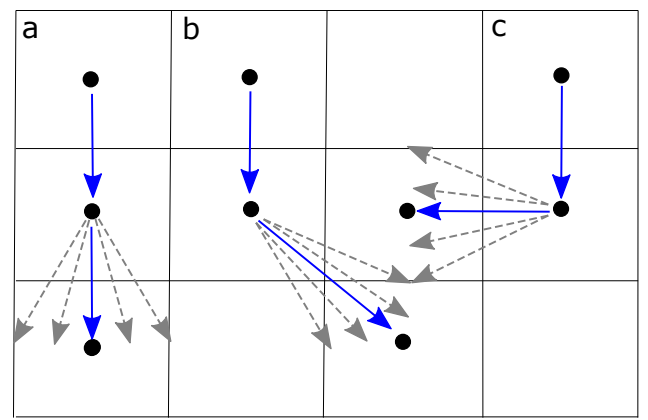

Figure 3: Schematic showing how radius of curvature is calculated for two stream segments. a) Cases of two straight segments (shown in blue arrows) are treated as if the actual angle between them ranges anywhere between $+22.5^{\circ}$ to $-22.5^{\circ}$ (shown in gray arrows). If one takes the average among these possible angles, the resulting inverse radius of curvature is $0.23 / d x$, where $d x$ is the cell size in the flow direction. b) We assume that a $45^{\circ}$ bend represents a continuum of possible angles between the two segments, ranging from $22.5^{\circ}-63.5^{\circ}$. Taking the mean of these possible angles results in a mean inverse radius of curvature of $0.67 / d x$. c) A $90^{\circ}$ bend in stream segments can range from $63.5^{\circ}-116.5^{\circ}$, giving a mean inverse radius of curvature of $1.37 / d x$.

\section{New model runs}

\subsection{Models with lateral erosion on from beginning.}

Model runs presented in the paper were created by initializing and running the model to steady state with vertical incision only. After the models reached steady state with vertical incision and the drainage network was established, the models were run with lateral erosion. Models can also be initialized with both lateral and vertical erosion and show no differences in topography or magnitude of lateral erosion at steady state when compared to models with lateral erosion turned on after the drainage network was established (Figure 4, Figure 5). The models were started with an initial condition of a slightly inclined slope with random noise, and lateral erosion only occurs after the drainage network is established $\sim 20$ ky of model time.

\subsection{Models with that account for channel width and channel contact with neigh- boring node}

Although channel width is not explicitly represented in the model we describe, the possibility exists that the "implied width" calculated by $W=k_{w} Q^{0.5}$ (where $k_{w}$ is a width coefficient and $Q$ is discharge) could be wider than a cell with a size $d x$. We wrote a modified version of the model presented in the paper where the calculated lateral erosion rate, $E_{l}$, is multiplied by a ratio of calculated channel width and $\mathrm{dx}, W_{c} / d x$. This modification adjusts lateral erosion rate to account for both the position of the channel within the model cell and cases where implied channel width is greater than the cell size. This modification reduces lateral erosion in small streams where channel width is less than $\mathrm{dx}$ and enhances lateral erosion where calculated channel width exceeds $\mathrm{dx}$. When $\mathrm{dx}=10$, nodes with drainage area greater than $1 \mathrm{e} 5$ have a calculated channel width greater than $10 \mathrm{~m}$, but the vast majority of model nodes (Figure 6) have a drainage area less than 1e5.

Figure 7 shows that the modified model where $E_{l}$ scales with $W_{c} / d x$, has the anticipated effect of narrowing valleys with small drainage areas and enhancing valley width where a large drainage area results in a calculated width greater than $\mathrm{dx}$. The overall effect of the modification to the 

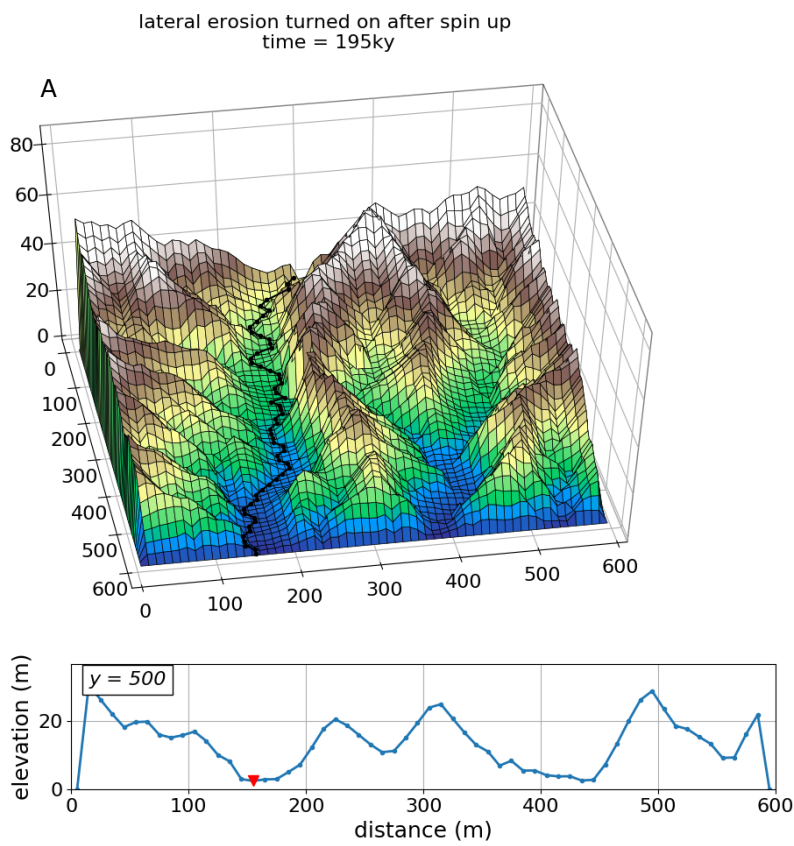
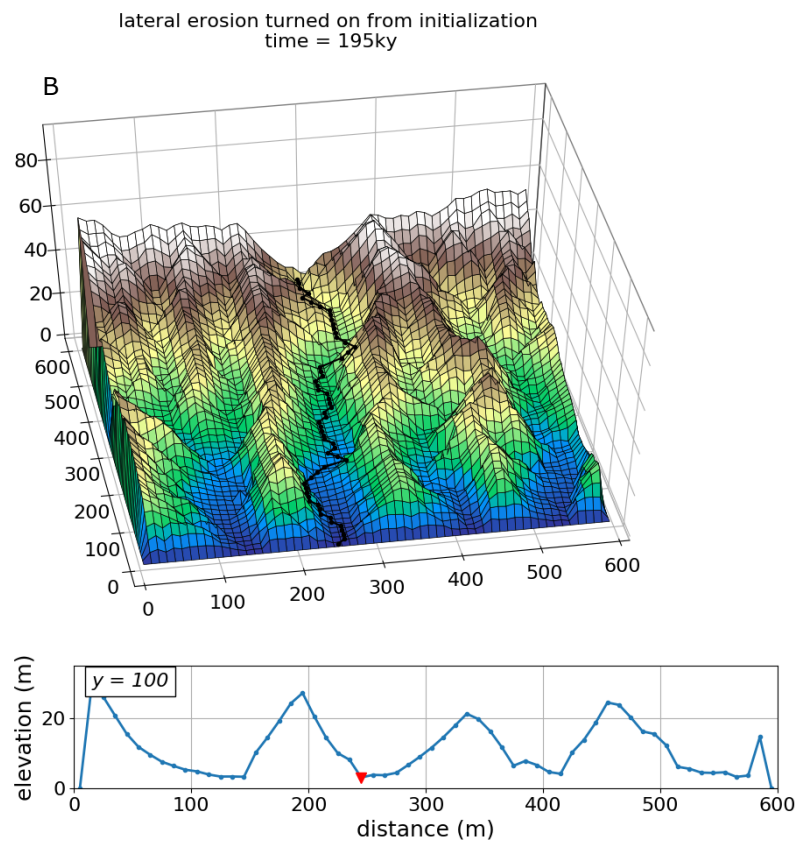

Figure 4: Topography of a) original models discussed in paper with lateral erosion turned on after drainage network is established and b) model with lateral erosion turned on from initialization.
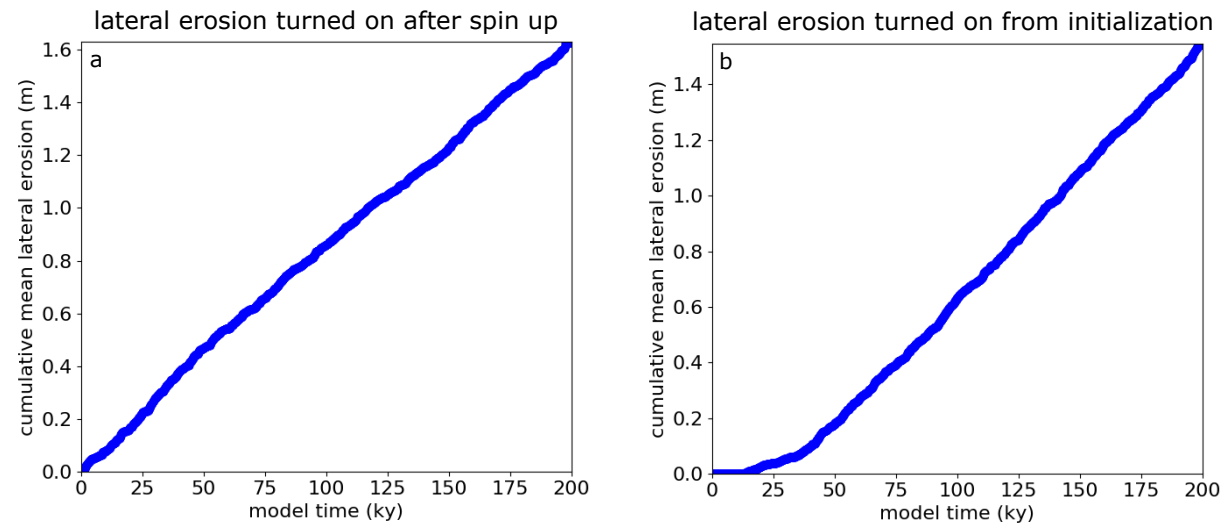

Figure 5: Cumulative lateral erosion averaged over the entire model domain for a) original models discussed in paper with lateral erosion turned on after drainage network is established and b) model with lateral erosion turned on from initialization.

model is subtle and we do not believe that it changes the results and conclusions from the original model. 

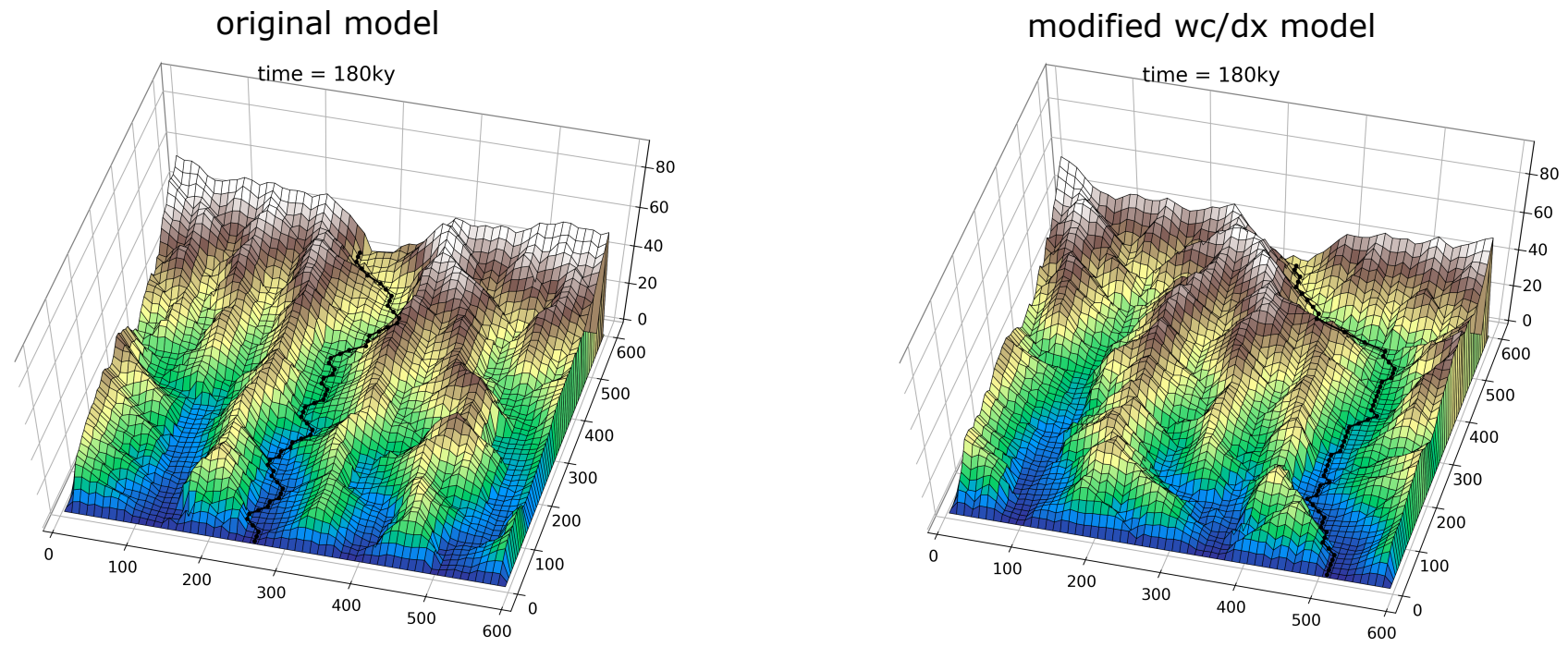

Figure 6: Topography after $180 \mathrm{ky}$ of model time for two undercutting-slump model runs with $\mathrm{dx}=10 \mathrm{~m}, \mathrm{~K}=1 e-4$, and $\alpha=0.8$. a) Topography from a model run using the original model configuration that does not account for the position of the channel in the cell in relation to the neighboring lateral node. b) Topography from a model run using the modified model where $E_{l}$ scales with $W_{c} / d x$. 

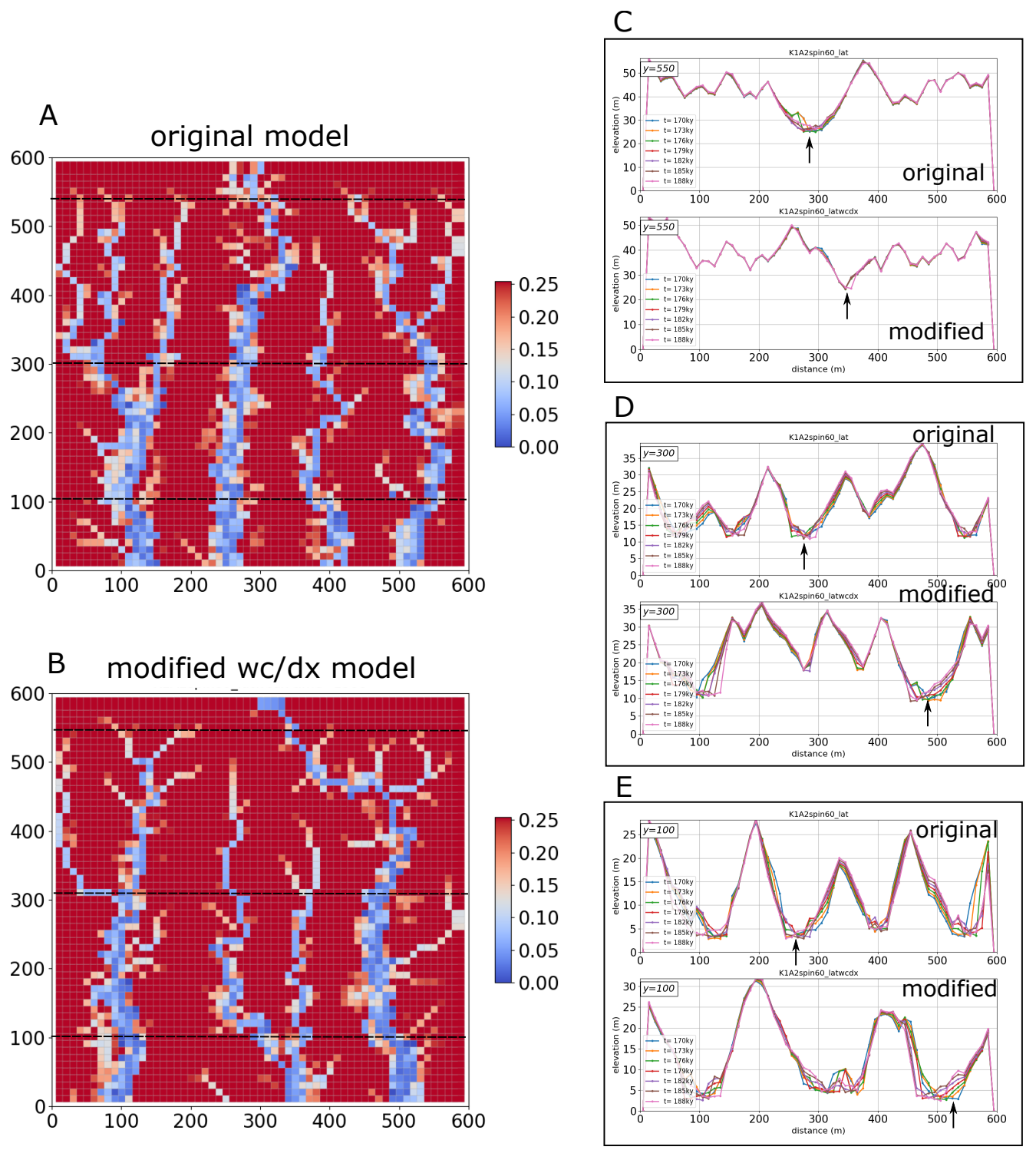

Figure 7: Slope maps showing wide, fluvially carved valleys in blue and hillslope-like areas in red at the end of the $200 \mathrm{ky}$ model run for A) the original model and B) the modified model. C, D, E) show cross sections from both model runs over the last $18 \mathrm{ky}$ of the model run. Cross sections are taken at $\mathrm{y}=550, \mathrm{y}=300$, and $\mathrm{y}=100$, indicated by black dashed lines on the slope maps. In $\mathrm{C}, \mathrm{D}, \mathrm{E}$, the cross section from the original model is on the top and the cross section from the modified model is on the bottom. Black arrows on the cross sections indicate the position of the main channel. C) at $\mathrm{y}=550$, drainage are is quite low and valley width in the modified model is narrow compared to the original model. D) At $\mathrm{y}=300$, the modified model appears to have a wider valley and more dynamic movement of valley walls. E) At $y=100$, the modified model clearly has a wider valley and more dynamic wall movement. 


\subsection{Changes in grid size in increased water flux models: Comparison among $\mathrm{dx}=10 \mathrm{~m}, 15 \mathrm{~m}, 20 \mathrm{~m}$}

This section shows figures from model runs with a period of increased water flux with $\mathrm{dx}=10 \mathrm{~m}$, $15 \mathrm{~m}$, and $20 \mathrm{~m}$. The original models presented in the paper were run with $\mathrm{dx}=10$, but when drainage area at the inlet is increased from $2 \mathrm{e} 4 \mathrm{~m}^{2}$ to $1.6 \mathrm{e} 5 \mathrm{~m}^{2}$, implied channel width (implied, that is, by the width-discharge relation embedded in $\mathrm{K}$ ) is larger than the grid-cell size. This issue is not unique to our particular model; any non-hydrodynamic LEM with sufficient resolution would face the same inconsistency. The relevant questions to answer here are: 1) how different is the magnitude of lateral erosion when one changes the grid size? and 2) how different are valley widths measured in the model with changes in grid size?

Figure 8 shows cumulative lateral erosion averaged over the model domain plotted against model time for the increased water flux model runs. The conclusion from this figure is that when using the total block erosion model formulation, increasing the grid size reduces the amount of lateral erosion that occurs on the model domain. All model runs in Figure 8 show increased lateral erosion during the period of increased water flux, 50-100 ky. The undercutting-slump models with $\mathrm{dx}=10 \mathrm{~m}, 15$ $\mathrm{m}$, and $20 \mathrm{~m}$ (Figure 8d-f) have about the same amount of total lateral erosion over the duration of the model runs, ranging from $1.5 \mathrm{~m}(\mathrm{dx}=10 \mathrm{~m})$ to $1.1 \mathrm{~m}(\mathrm{dx}=20 \mathrm{~m})$. The total block erosion models have decreasing lateral erosion with increasing grid size, ranging from $0.4 \mathrm{~m}(\mathrm{dx}=10 \mathrm{~m})$ to $0.14 \mathrm{~m}(\mathrm{dx}=20 \mathrm{~m})$. When $\mathrm{dx}=10 \mathrm{~m}$, the cumulative mean lateral erosion using the total block erosion model (Figure 8a) looks similar in pattern to the undercutting-slump models (Figure 8d-f), showing increased lateral erosion during the periods of increased water flux. When $\mathrm{dx}$ is increased to $15 \mathrm{~m}$ and $20 \mathrm{~m}$ (Figure 8b,c), the volume that must be eroded before the model topography is changed is increased, resulting in periods of time when no lateral erosion occurs in the model. Periods in the model with no lateral erosion are indicated by horizontal series of markers in Figure $8 \mathrm{~b}, \mathrm{c}$. The longest period with no lateral erosion is in the model with $\mathrm{dx}=20 \mathrm{~m}$, during the first 37 ky of the period of increased water flux (Figure 8c). Increased water flux resulted in immediate increased vertical incision in all models, and increased lateral erosion after a lag period in the total block erosion models (see Figure 9 in main paper). The lag period for lateral erosion to occur in total block erosion models increases with $\mathrm{dx}$, up to $37 \mathrm{ky}$ when $\mathrm{dx}=20$.

Figure 9 shows mean valley width averaged over the length of the channel plotted against the duration of the model runs for model runs with increased water flux and $\mathrm{dx}=10 \mathrm{~m}, 15 \mathrm{~m}$, and 20 m. Figure 9a and Figure 9d are also shown in Figure 7c,d in the main paper and included again here to compare with model runs where $\mathrm{dx}=15 \mathrm{~m}$ and $20 \mathrm{~m}$.

The increased water flux model runs using the total block erosion model with $\mathrm{y}=10 \mathrm{~m}, 15 \mathrm{~m}$, and $20 \mathrm{~m}$ are shown in Figure 9a,b,c. In all cases, mean valley width for each value of dx is 1.5 times larger than the $\mathrm{dx}$ value, indicating that the valley is 1.5 cells wide, and quite stable for the first 50 ky of the model runs. The differences in model runs are evident at the onset of the increased water flux, between $50 \mathrm{ky}$ and $100 \mathrm{ky}$. In the models where $\mathrm{dx}=10$, valley width increases with increased water flux. In models with $\mathrm{dx}=15$ and 20 , valley width generally increased by about $10 \mathrm{~m}$ from 50-100 ky. The most striking difference shown in this figure is in the low $\mathrm{K}$ model run shown in Figure 9c. Figure 9c shows mean valley width for model runs where $d x=20$. The most interesting feature in this plot is the large increase in valley width in the low $\mathrm{K}$ model after the cessation of increased water flux. The $\mathrm{dx}=20$ low $\mathrm{K}$ model run shows only a very slight increase in valley width with increased water flux and responded primarily by incising a deep valley (see also Figure 8c). When increased water flux stopped and drainage area at the inlet was again $2 \mathrm{e} 4 \mathrm{~m}^{2}$, the deep gorge that was carved in the upper valley began to flatten through both aggradation and lateral erosion, similar to the model run detailed in Figure 8 in the main paper. Lateral erosion in total block 

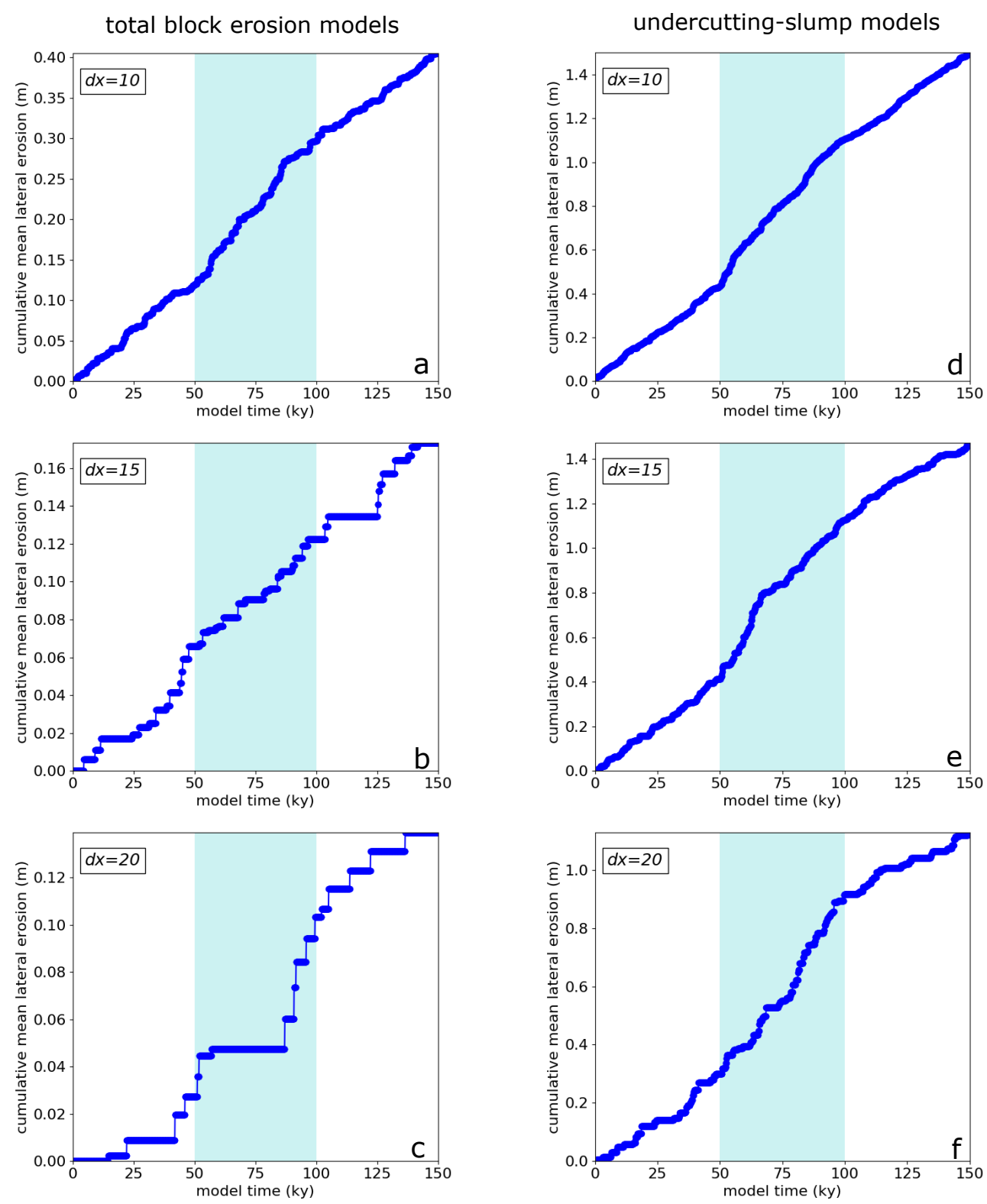

Figure 8: Cumulative lateral erosion averaged over the entire model domain for model runs with increased water flux and $\mathrm{K}=0.00005$. Total block erosion models (a,b,c) and undercutting slump models (d,e,f) are shown with $\mathrm{dx}=10 \mathrm{~m}, 15 \mathrm{~m}$, and $20 \mathrm{~m}$. Light blue shading indicates periods of increased water flux, between 50 and 100 ky model time.

erosion models scales with valley wall height. As water flux decreases and aggradation begins, the valley height is decreased, making lateral erosion possible in the low $\mathrm{K}$ model runs with a larger grid size. The conclusion is that when using the total block erosion model, where lateral erosion scales with valley height, grid size affects model outcomes, particularly when $\mathrm{K}$ is low. Using the total block erosion model, larger grid size can result in less lateral erosion, more narrow valleys, and longer response times for lateral erosion to occur.

Figure 9d,e,f shows the increased water flux model runs using the undercutting slump model 
with $\mathrm{y}=10 \mathrm{~m}, 15 \mathrm{~m}$, and $20 \mathrm{~m}$. While the patterns of mean valley width are similar in for all values of $\mathrm{dx}$, in the $\mathrm{dx}=15$ and $\mathrm{dx}=20$ models runs, mean valley width is larger than the $\mathrm{dx}=10$ model both before and during the period of increased water by about 10 to 20 meters. This warrants a closer look at the actual valley width that emerges from each model in Figures 10-12. The conclusion from Figures 10-12 is that valley widths in the downstream sections of the model domain estimated from cross sections and slope maps are quite close among models with $\mathrm{dx}=10 \mathrm{~m}, 15 \mathrm{~m}$, and $20 \mathrm{~m}$. The comparison made in Figures 10-12 suggests that the increased values of mean valley width with increasing dx shown in Figure 9d,e,f, are not very problematic when comparing models with different grid sizes. We conclude that model grid size affects magnitude of lateral erosion and mean valley width when using the total block erosion model formulation, but does not seem to result in significant differences when using the undercutting-slump model formulation.
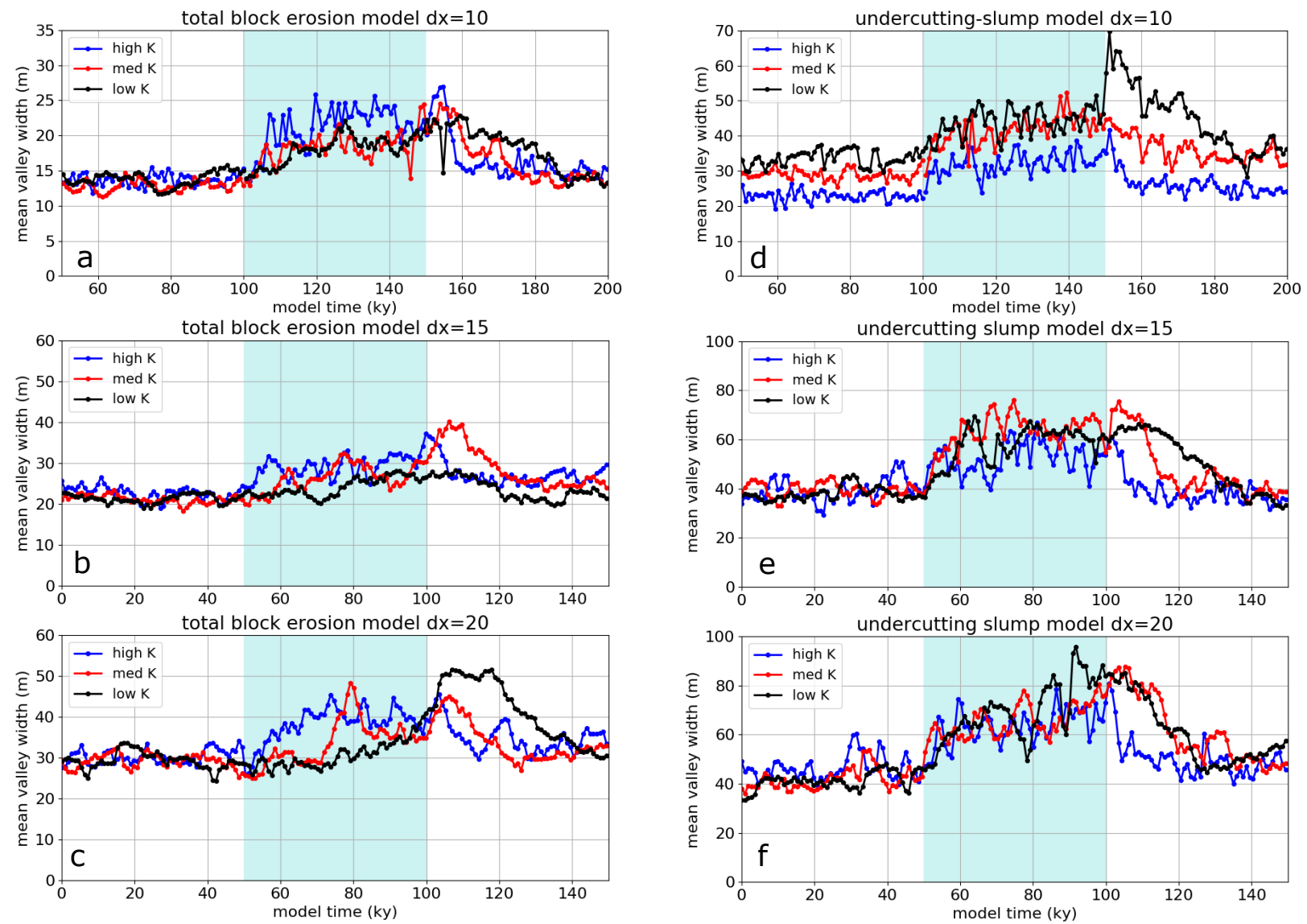

Figure 9: Mean valley width through time for the increased water flux models using the total block erosion model $(\mathrm{a}, \mathrm{b}, \mathrm{c})$ and the undercutting slump model $(\mathrm{d}, \mathrm{e}, \mathrm{f})$ with $\mathrm{dx}=10,15$, and $20 \mathrm{~m}$. Panels a and $\mathrm{d}$, with $\mathrm{dx}=10 \mathrm{~m}$ are the same as Figure $7 \mathrm{c}, \mathrm{d}$ in the main paper and have increased water flux from $100 \mathrm{ky}$ to $150 \mathrm{ky}$. The models with $\mathrm{dx}=15 \mathrm{~m}$ and $20 \mathrm{~m}$ were run for $150 \mathrm{ky}$ with increased water from $50 \mathrm{ky}$ to $100 \mathrm{ky}$. Note the difference in scale between the panels in the figure. 

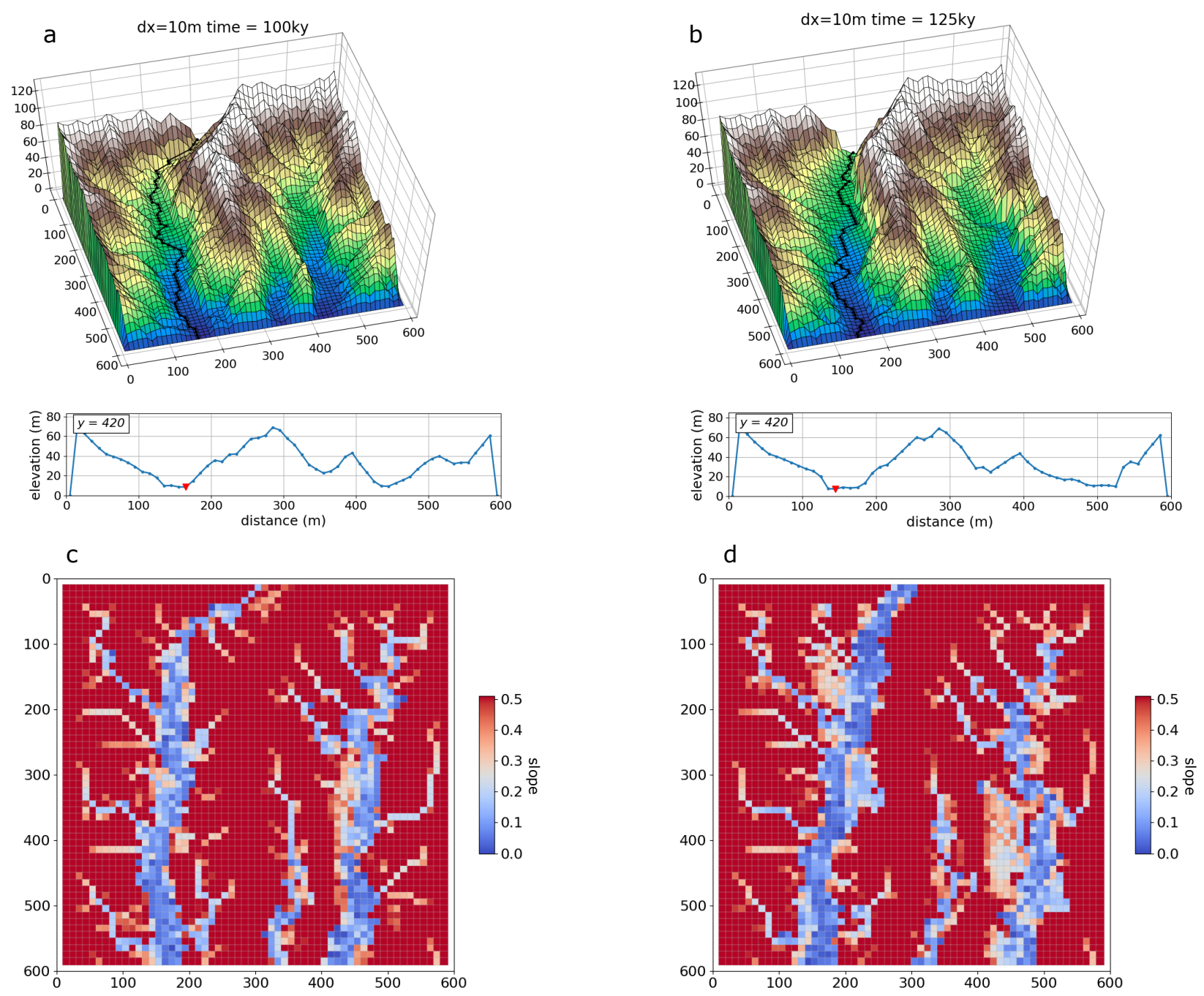

Figure 10: Undercutting-slump model with increased water flux models with original grid size of $\mathrm{dx}=10$. At $\mathrm{t}=0$ (before increased water flux), valley width at $\mathrm{y}=420$ is $30 \mathrm{~m}$ wide according to the cross section, and is $40 \mathrm{~m}$ wide according to the slope map. 40 meters was determined from 4 blue/light squares, each $10 \mathrm{~m}$ wide. At $\mathrm{t}=25 \mathrm{ky}$ (after $25 \mathrm{ky}$ of increased water flux), valley width at $\mathrm{y}=420$ is $40 \mathrm{~m}$ wide from the cross section, and is $50 \mathrm{~m}$ wide from the slope map. 50 meters was determined from 5 blue/light squares. 

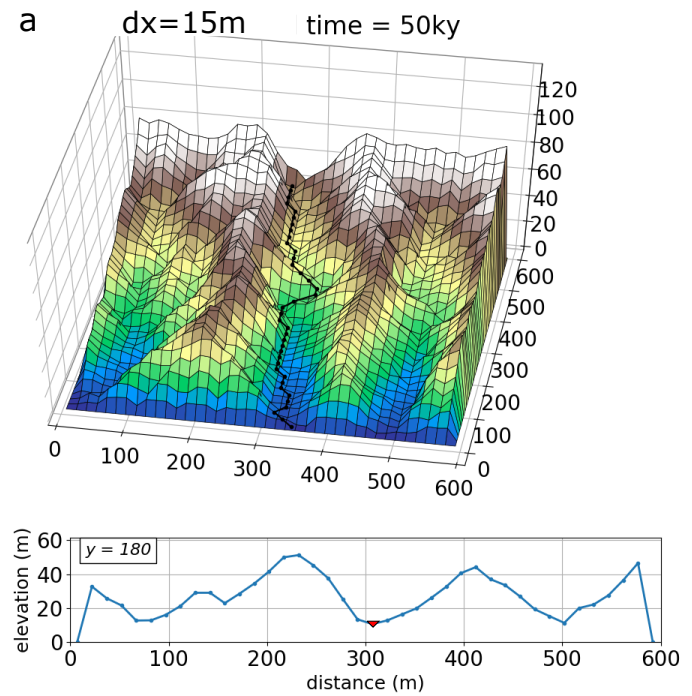

C

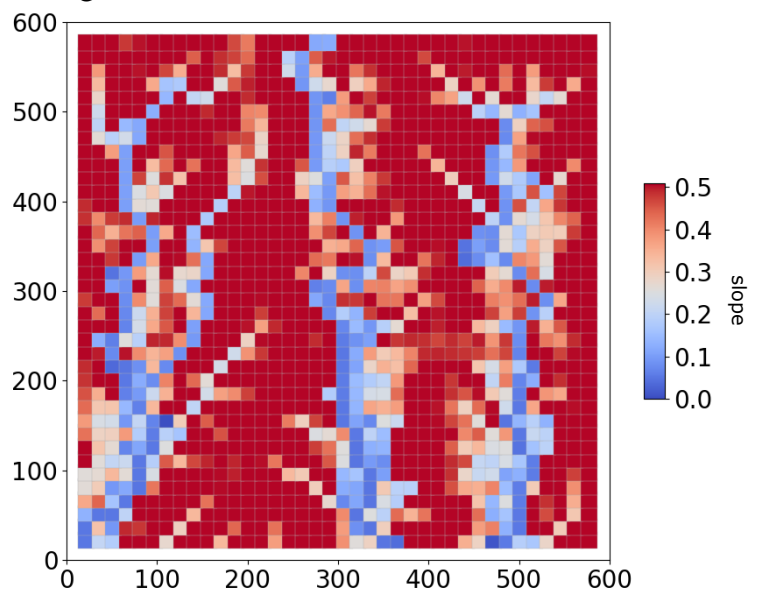

b $\quad \mathrm{dx}=15 \mathrm{~m} \quad$ time $=75 \mathrm{ky}$
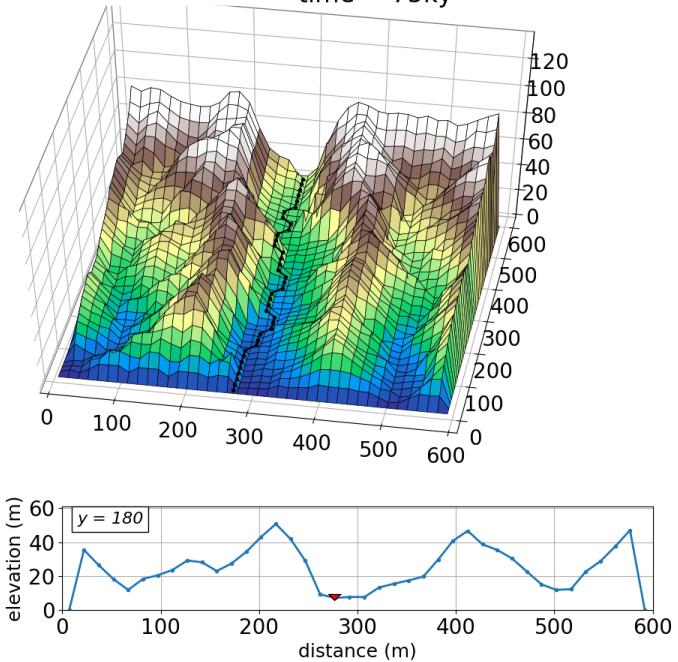

d

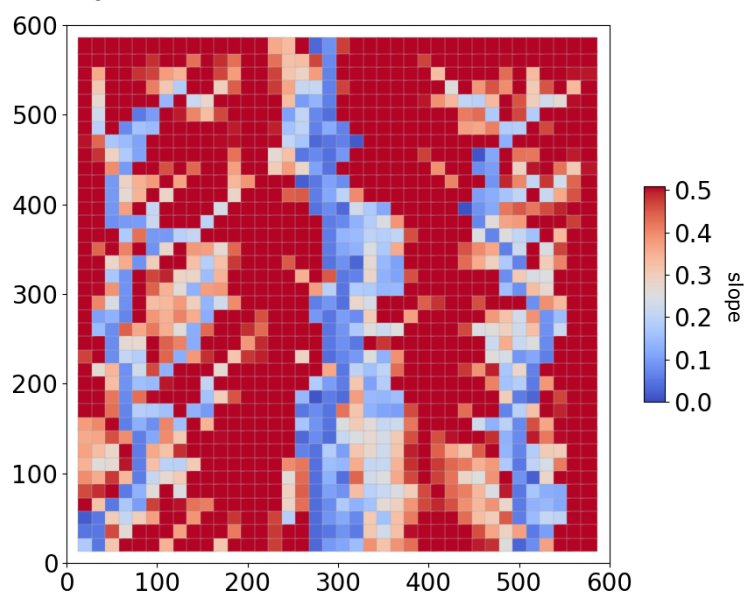

Figure 11: Undercutting-slump model with increased water flux models with new grid size of dx=15. At $\mathrm{t}=50 \mathrm{ky}$ (before increased water flux), valley width at $\mathrm{y}=180$ is $30 \mathrm{~m}$ wide according to the cross section, and is $30 \mathrm{~m}$ wide according to the slope map. 30 meters was determined from 2 blue/light squares, each $15 \mathrm{~m}$ wide. At $\mathrm{t}=75 \mathrm{ky}$ (after $25 \mathrm{ky}$ of increased water flux), valley width at $\mathrm{y}=180$ is $45 \mathrm{~m}$ the cross section, and is $45 \mathrm{~m}$ wide from the slope map. 45 meters determined from 3 blue/light squares, each $15 \mathrm{~m}$ wide. 

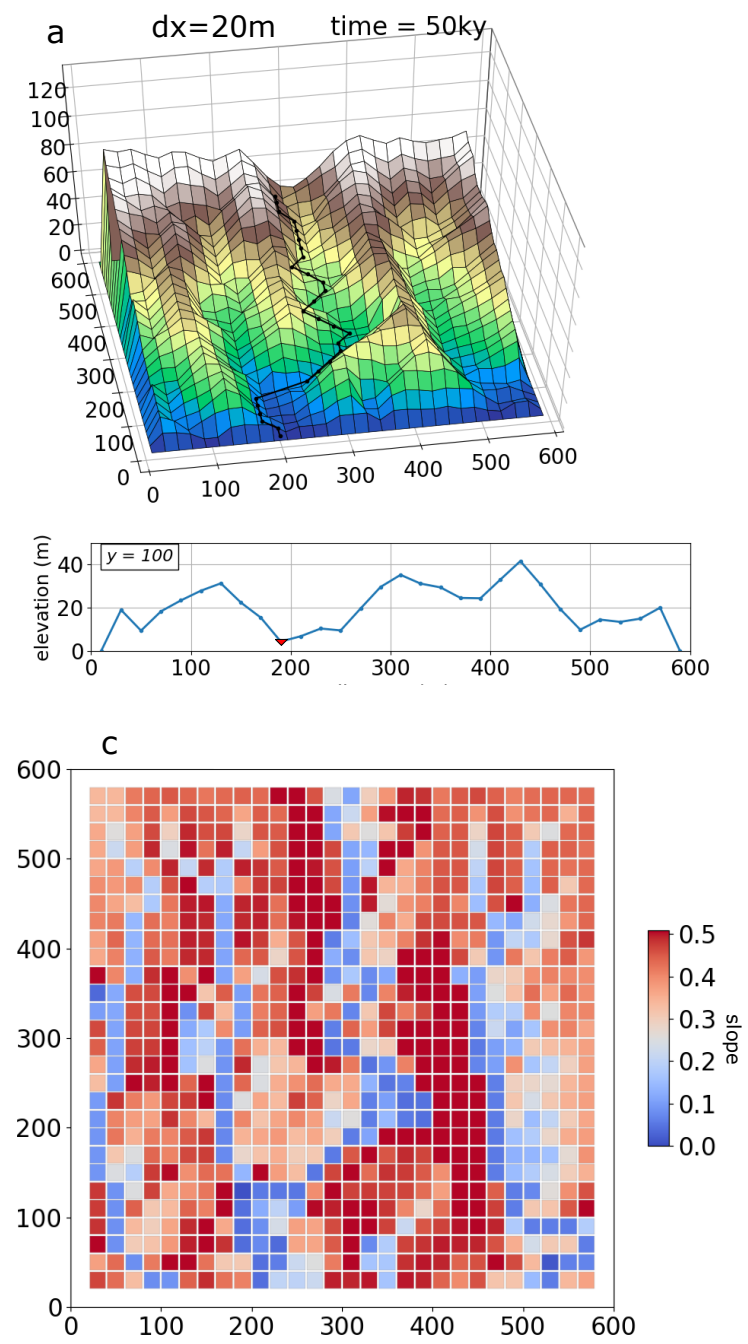
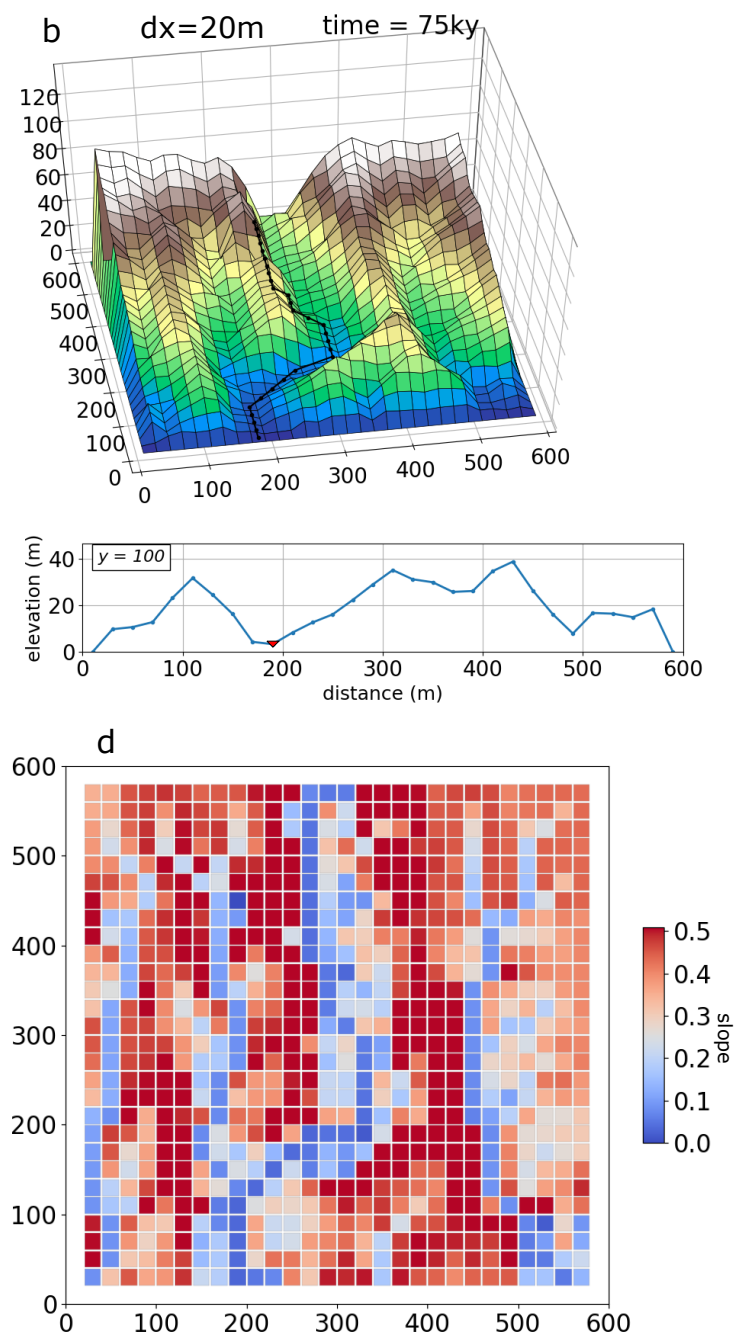

Figure 12: Undercutting-slump model with increased water flux models with new grid size of dx=20. At $\mathrm{t}=50 \mathrm{ky}$ (before increased water flux), valley width at $\mathrm{y}=100$ is about $20 \mathrm{~m}$ wide according to the cross section, and is $40 \mathrm{~m}$ wide according to the slope map. 40 meters was determined from 2 blue/light squares, each $20 \mathrm{~m}$ wide. At $\mathrm{t}=75 \mathrm{ky}$ (after $25 \mathrm{ky}$ of increased water flux), valley width at $\mathrm{y}=100$ is $40 \mathrm{~m}$ wide according to the cross section, and is $60 \mathrm{~m}$ wide according to the slope map. 60 meters was determined from 3 blue/light squares, each $20 \mathrm{~m}$ wide. 